\title{
The class I phosphoinositide 3-kinases $\alpha$ and $\beta$ control antiphospholipid antibodies-induced platelet activation
}

Running title : PI3K and antiphospholipid antibodies induce platelet activation

Anne-Dominique Terrisse ${ }^{1}$, Pierre-Alexandre Laurent ${ }^{1}$, Cédric Garcia ${ }^{2}$, Marie-Pierre Gratacap $^{1}$, Bart Vanhaesebroeck ${ }^{3}$, Pierre Sie ${ }^{1,2}$, Bernard Payrastre ${ }^{1,2}$

${ }^{1}$ INSERM, U1048 and Université Toulouse 3, Institut des Maladies Métaboliques et Cardiovasculaires (I2MC), CHU-Rangueil, F-31300 Toulouse, France.

${ }^{2} \mathrm{CHU}$ de Toulouse, Laboratoire d'Hématologie, Toulouse Cedex, France

${ }^{3}$ UCL Cancer Institute, University College London, 72 Huntley Street, London WC1E 6BT, United Kingdom.

Keywords: Antiphospholipid antibodies, blood platelets, phosphoinositide 3-kinases, thrombosis

Nonstandard abbreviations and acronyms: Akt, protein kinase B; PI3K, phosphoinositide 3kinase; TLR, Toll Like Receptors.

The authors have no conflict of interest to report.

Corresponding author: Anne-Dominique Terrisse, Inserm U1048, I2MC, 1 Avenue Jean Poulhés, BP 84225, 31432 Toulouse Cedex 04, France. Tel.: +335 3122 4150; Fax: +33 5 6132 5621. E-mail: anne-dominique.terrisse@inserm.fr 


\section{ABSTRACT}

Objective - The antiphospholipid syndrome (APS) is an autoimmune disease characterized by the presence of antiphospholipid antibodies (aPL) associated with increased thrombotic risk and pregnancy morbidity. Although aPL are heterogeneous auto-antibodies, the major pathogenic target is the plasma protein $\beta 2$-Glycoprotein 1 . The molecular mechanisms of platelet activation by aPL remain poorly understood. Here, we explored the role of the class IA phosphoinositide 3-kinase (PI3K) $\alpha$ and $\beta$ isoforms in platelet activation by aPL.

Approach and Results - Compared to control IgG from healthy individuals, the IgG fraction isolated from patients with APS potentiates platelet aggregation induced by low dose of thrombin in vitro and increases platelet adhesion and thrombus growth on a collagen matrix under arterial shear rate through a mechanism involving glycoprotein $\mathrm{Ib}$ (GPIb) and Toll Like Receptor 2 (TLR-2). Using isoforms-selective pharmacological PI3K inhibitors and mice with megakaryocyte/platelet lineage-specific inactivation of class IA PI3K isoforms, we demonstrate a critical role of the PI3K $\beta$ and PI3K $\alpha$ isoforms in platelet activation induced by aPL.

Conclusions - Our data show that aPL potentiate platelet activation through GPIb $\alpha$ and TLR-2 via a mechanism involving the class IA PI3K $\alpha$ and $\beta$ isoforms, which represent new potential therapeutic targets in the prevention or treatment of thrombotic events in patients with APS. 


\section{INTRODUCTION}

The antiphospholipid syndrome (APS) is characterized by the occurrence of arterial or venous thrombosis or pregnancy morbidity associated with the persistent antiphospholipid antibodies (aPL). Sera from patients contain a heterogeneous group of antibodies that bind to various plasma proteins with high affinity for lipids, such as $\beta 2$-glycoprotein-1 ( $\beta 2 \mathrm{GP} 1)$. Anti- $\beta 2$ GP1 autoantibodies are an independent risk factor for thrombotic complications (1) and it is now clear that thrombogenic antibodies are mainly IgG directed against $\beta 2 \mathrm{GP} 1$ (2). For instance, passive transfer of specific anti- $\beta 2 \mathrm{GP} 1$ autoantibodies of the $\operatorname{IgG}$ class derived from APS patients with prior thromboembolic events to mice potentiates arterial thrombus formation following vascular injury in this model organism (3). Although antibodies directed to domain I of $\beta 2 \mathrm{GP} 1$ are positively correlated with thrombotic and pregnancy complications, several studies suggest the existence of different subpopulations of anti- $\beta 2 \mathrm{GP} 1$ antibodies recognizing distinct epitopes on $\beta 2 \mathrm{GP} 1$ and having different pathological effects $(1,4-7)$. Importantly, besides anti- $\beta 2 \mathrm{GP} 1$ antibodies, it is currently thought that a second hit is necessary to trigger the thrombotic events in APS. In animal models, passive infusion of human IgG purified from APS patients results in excessive thrombus formation only upon vascular injury $(3,8-10)$ or following priming with endotoxin (11). The pathogenic antibodies are known to contribute to the activation of different cells including platelets, monocytes, endothelial and trophoblastic cells. Several membrane receptors present on these cells have been shown to interact with $\beta 2 \mathrm{GP} 1$ dimerized by antibodies to $\beta 2 \mathrm{GP} 1$, including Toll Like Receptors (TLR) 2 and 4, GPIb $\alpha$ and ApoER2 (12-16). Among the targets of aPL, platelets play a pivotal role in APS. Notably, they are required to increase the activation of the endothelium and for fibrin generation (17). Anti- $\beta 2 \mathrm{GP} 1$ antibodies potentiate platelet aggregation induced by 
suboptimal doses of agonists $(7,18)$ and can promote the formation of a platelet-rich thrombus in vivo (3). In platelets, in the presence of aPL, dimeric $\beta 2 \mathrm{GP} 1$ interact with GPIb $\alpha$ and ApoER2, which form a complex at the membrane and are both required for platelet activation (15-16, 19-20). However, the molecular mechanisms of platelet activation by aPL downstream of these receptors remain poorly understood.

Class IA phosphoinositide 3-kinases (PI3K) are lipid kinases involved in the regulation of signal transduction mechanisms (21). Following cell surface receptor activation, they generate the lipid second messenger phosphatidylinositol 3,4,5-triphosphate, which serves as plasma membrane docking sites for several important signaling proteins that harbor pleckstrin-homology domains. Thus, this lipid modulates the localization and activity of intracellular protein effectors. One of the best characterized effector of class IA PI3K is the PH-domain containing serine/threonine kinase Akt. Class IA PI3K and Akt play important roles in platelet activation by physiological agonists $(22,23)$. As PI3K inhibitors are in advanced development for the treatment of several human pathologies, a better knowledge of the implication of PI3K in platelet activation by aPL antbodies could be useful to develop new therapeutic strategies in the APS. In the present study, we have explored the role of the broadly expressed class IA PI3K $\alpha$ and $\beta$ isoforms in platelet activation by aPL from APS patients using pharmacological inhibitors and genetic approaches in mouse.

\section{MATERIALS AND METHODS}

Materials. The anti- human $\beta 2 \mathrm{GP} 1$ antibody and the recombinant $\beta 2 \mathrm{GP} 1$ protein were from Hyphen BioMed. The anti-human CD42b antibody (clone AN51) was from Dako, the anti human TLR2 antibody was from eBioscience, the CD36 antibody (clone FAG152) was from 
Beckman Coulter and the anti P-Akt $\mathrm{S}^{473}$ antibody was from Cell Signaling. PI3K inhibitors were from Sigma-Aldrich (wortmannin, LY294002), Santa Cruz (TGX221), Selleckchem (AZD6482, CAL-101) and Activebiochem (INK-1117). All other reagents were purchased from Sigma-Aldrich unless otherwise indicated.

Human blood samples. Citrated blood samples were obtained from three healthy donors and three APS patients diagnosed at the Department of Hematology, Toulouse University Medical Center, after informed consent obtained in accordance with the Declaration of Helsinki. The Institutional Review Board of the Hospital approved the study. Inclusion criteria were an antecedent of thrombotic event associated with triple aPL seropositivity (lupus anticoagulant, and high-titer antibodies against cardiolipin and $\beta 2 \mathrm{GP} 1$ ), according to the revised criteria for APS of the ISTH (24). Blood from healthy donors was purchased from the Etablissement Français du Sang, Toulouse. Citrated blood from healthy donors was used immediately for flow and platelets experiments. Sera from APS patients and healthy donors, obtained by centifugation $(1000 \mathrm{~g}, 15 \mathrm{~min})$ and decomplementation $\left(56^{\circ} \mathrm{C}, 1 \mathrm{~h}\right)$ of blood, were stored at $80^{\circ} \mathrm{C}$ until IgG preparation. The IgG fraction (APS patients and healthy donors) was purified by batch affinity using a protein G Sepharose affinity chromatography (protein-G-sepharose 4 fast flow kit, Ge Healthcare). IgG were eluted with Tris-glycine ( $\mathrm{pH} 2.5)$. After $\mathrm{pH}$ neutralization with Tris- $\mathrm{HCl}, \mathrm{pH}$ 9.0, the eluted fractions were dialyzed against Phosphate Buffer Saline (137 mM NaCl, 2.7mM KCl, $10 \mathrm{mM} \mathrm{Na2HPO4,} 1.76 \mathrm{mM} \mathrm{KH2PO4} \mathrm{)} \mathrm{and}$ assessed for anti- $\beta 2 \mathrm{GP} 1$ activity by Elisa (Diagnostica Stago). Anti- $\beta 2 \mathrm{GP} 1$ activity was negative in control $\mathrm{IgG}(<20 \mathrm{IU} / \mathrm{ml})$ and highly positive $(>160 \mathrm{IU} / \mathrm{ml})$ in the $\mathrm{IgG}$ fractions of the APS patients. Antibody purity was assessed by SDS-PAGE and Coomassie blue staining.

Preparation of human platelets. Human platelets from healthy donors were isolated from 
blood collected under citrate by successive centrifugation steps. Briefly, they were washed in

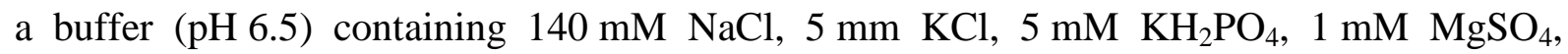
$10 \mathrm{mM}$ HEPES, $5 \mathrm{mM}$ glucose and $0.35 \%$ bovine serum albumin (BSA) (w/v). The same buffer containing $1 \mathrm{mM} \mathrm{CaCl}_{2}$ was added to the final suspension, and $\mathrm{pH}$ was adjusted to 7.4.

Mice. Mice used in the study were of C57B1/6 genetic background. They were cared in the U1048-Toulouse Rangueil animal facility according to institutional guidelines. All animal procedures were in accordance with the guidelines of the Midi-Pyrénées Ethics Committee on Animal Experimentation and with the French Ministry of Agriculture license (http://anexplo.genotoul.fr). PF4-Cre/p110 $\beta^{\text {flox/flox }}$ mice (further referred to as p110 $\beta$ null) and PF4-Cre/p110 $\alpha^{\text {flox/flox }}$ mice were generated as previously described $(25,26)$. These animals (C57B1/6 genetic background) showed normal size and count of platelets as described (26).

Preparation of murine platelets. Whole blood was drawn from the inferior vena cava of anesthetized 8-20 week-old mice into a syringe containing acid citrate dextrose (1:9 v/v). Mouse platelets were then prepared as previously described (27).

Light transmission aggregometry. Aggregation of washed platelets from healthy blood donors or mice was induced by thrombin $(0.035 \mathrm{U} / \mathrm{ml})$. Platelet aggregation was monitored under continuous stirring at $1000 \mathrm{rev} \cdot \mathrm{min}^{-1}$ at $37^{\circ} \mathrm{C}$ using a turbidimetric method in dualchannel aggregometer (Chronolog, Stago). When indicated, human platelets were preincubated for $10 \mathrm{~min}$ with anti-CD42b $(1.8 \mu \mathrm{g} / \mathrm{ml})$, anti-TLR2 $(6.6 \mu \mathrm{g} / \mathrm{ml})$, or pharmacologic class I PI3K inhibitors (wortmannin: 50 nM, LY294002: 25 nM, TGX-221: $500 \mathrm{nM}, \mathrm{INK}-1117$ : $500 \mathrm{nM}$ in washed platelets, $1 \mu \mathrm{M}$ in whole blood under flow, AZD- 
6482: $5 \mu \mathrm{M}$, CAL 101: $2.5 \mathrm{nM})$. aPL IgG or control IgG $(50 \mu \mathrm{g} / \mathrm{ml})$ were added to platelet suspension adjusted to $10^{8} / \mathrm{ml}, 5 \mathrm{~min}$ before addition of agonist.

Western Blotting. Platelet lysates were analyzed as previously described (25) using the anti P-Akt $\mathrm{S}^{473}$ antibody.

In vitro model of thrombosis under flow conditions. Glass microcapillaries (Cellix system) were coated with $50 \mu \mathrm{g} / \mathrm{ml}$ type I collagen from equine tendon for $1 \mathrm{~h}$ at $37^{\circ} \mathrm{C}$ and saturated with a solution of $0.5 \%$ bovine serum albumin (fatty acid free) in Phosphate Buffer Saline. Human (healthy donors) or mouse blood was drawn into heparin $(10 \mathrm{IU} / \mathrm{ml})$ and $\mathrm{DiOC}_{6}(2$ $\mu \mathrm{M}, 15 \mathrm{~min}$ at $37^{\circ} \mathrm{C}$ ) was used to label platelets in whole blood. Antibodies (control or aPL IgG) were added at $16.6 \mu \mathrm{g} / \mathrm{ml}$ in blood $5 \mathrm{~min}$ before perfusion. When indicated, anti-TLR2 $\mathrm{Ab}(6.6 \mu \mathrm{g} / \mathrm{ml})$ or anti-CD42b Ab $(4.5 \mu \mathrm{g} / \mathrm{ml}), \mathrm{PI} 3 \mathrm{~K} \alpha$ inhibitor (INK-1117, $1 \mu \mathrm{M})$ or PI3K $\beta$ inhibitor (AZD-6482, $1 \mu \mathrm{M}$ ) were preincubated for $5 \mathrm{~min}$ before aPL IgG addition. Blood was then perfused through the microfluidic system for $3 \mathrm{~min}$ at an arterial shear rate of $1500 \mathrm{~s}^{-}$ 1 (60 dyne $\left./ \mathrm{cm}^{2}\right)$. Platelet adhesion and thrombus formation were visualized with an epifluorescence microscope (Axiovert 200; Zeiss) with a 40X oil immersion objective (PlanApo 40x/1.3 Oil DIC UVVIS-IR), light source was provided by Colibri LED System (Zeiss) and recording in real time (acquisition rate: 1 frame every $10 \mathrm{sec}$ ) was performed via a high resolution CCD cooled camera (Orca-R2, Hamamatsu). Image sequences of the time lapse recording and analysis of surface coverage were performed using Image $\mathbf{J}$ software. Thrombus volume was calculated by thresholding of surface covered by thrombi on slice of Z-stack images and addition of voxel (automatically converted into $\mu \mathrm{m}^{3}$ by Zen ${ }^{\circledR}$ Zeiss software). 
Statistical Analysis. All data are presented as the mean \pm SEM of at least three independent experiments. Statistical significance was analysed using unpaired Student's test using Microsoft Excel 2007. Significance was set as $\mathrm{p}<0.05$.

\section{RESULTS}

In line with expectations, the titer of anti- $\beta 2 \mathrm{GP} 1$ in the purified IgG from the three APS patients (referred as aPL IgG hereafter) was highly positive (> $160 \mathrm{IU} / \mathrm{ml}$ ), as compared to the titer $(<20 \mathrm{IU} / \mathrm{ml})$ in the IgG preparation from the three healthy donors (referred to as control IgG hereafter). Interestingly, when washed human platelets from healthy blood donors were analyzed by flow cytometry for the presence of $\beta 2 \mathrm{GP} 1$, this protein was easily detected at the surface of platelets, irrespective of the addition of plasma or recombinant $\beta 2 \mathrm{GP} 1$ (Supplementary Figure 1), indicating that a fraction of $\beta 2 \mathrm{GP} 1$ interacts with circulating platelets.

\section{$\underline{\text { Platelet sensitization by aPL IgG }}$}

Consistent with previous reports (18), preincubation of washed human platelets with aPL IgG strongly increased platelet aggregation in response to a subactivating dose of thrombin $(0.035$ $\mathrm{U} / \mathrm{ml}$ ) (Figure 1A). The aPL from the three APS patients displayed comparable potentiating activity.

The prothrombotic activity of aPL IgG on thrombus formation was assessed using an integrated flow-based assay in which whole blood from healthy donors was perfused over a collagen matrix under flow conditions corresponding to physiological arterial shear rates. Under these conditions, the platelet glycoprotein (GP) Ib/V/IX mediates initial adhesion of platelets to vonWillebrand factor bound to collagen fibers. This induces a transient platelet adhesion (also called rolling), allowing platelets to interact with collagen through GPVI and $\alpha_{2} \beta 1$ thereby culminating in firm adhesion and thrombus formation. Accordingly, platelet adhesion was inhibited by addition of a monoclonal antibody to GPIb (CD42b) 
(Supplementary Figure 2B).

As shown in Figure $1 \mathrm{~B}$ and $\mathrm{C}$, compared to control, addition of aPL IgG significantly increased the surface covered by fluorescent platelets and the volume of the thrombi formed.

\section{$\underline{\text { Platelet sensitization by aPL IgG is dependent on membrane receptors GPIb and TLR2 }}$}

To further characterize the effect of aPL we next tested the impact of antibodies directed against the extracellular domain of GPIb $\alpha$, which has been shown to contribute to the plateletactivating effect of anti- $\beta 2 \mathrm{GP} 1$ antibody- $\beta 2 \mathrm{GP} 1$ complex (14), and to TLR2, which has been described as one of the endothelial receptors for the anti- $\beta 2 \mathrm{GP} 1$ antibody - $\beta 2 \mathrm{GP} 1$ complex (28). TLR2 has also been implicated in mediating the pathogenic effects of aPL on monocytes (12; for a review see 29) and is present on the platelet surface (28, 30-32). An antibody directed against the extracellular domain of GPIb $\alpha$ strongly inhibited the effect of aPL on thrombin-induced platelet aggregation (Figure 2A). Similarly, addition of a blocking antibody to TLR2 strongly inhibited the effect of aPL $\operatorname{IgG}$ on platelet aggregation induced by low concentration of thrombin (Figure 2A). A control antibody against the extracellular domain of the CD36, one of the major glycoprotein of the platelet surface which serves as a receptor for thrombospondin and oxidized lipids, had no effect on aPL-induced platelet activation (100.3 $\pm 9 \%$ of aPL2 effect, not shown). TLR2 blocking antibodies also decreased the effect of aPL on platelet adhesion and thrombus formation onto a collagen matrix under arterial flow conditions (Supplementary Figure 2 and Figure 2B). As expected, a GPIb $\alpha$ blocking antibody abolished platelet thrombus formation on collagen (Supplementary Figure 2 and Figure 2B), since this process requires initial binding to vonWillebrand via GPIb, and thus cannot be used to test the specific effect of aPL IgG in this test system.

Overall, these data indicate that GPIb $\alpha$ and TLR2 are both involved in mediating the potentiating effect of aPL on platelet activation, possibly through the formation of a multi- 
protein complex, as observed in other cells involved in the pathophysiology of APS $(15,33)$. Given that the aPL from the three patients displayed the same potentiating activity, they were hereafter used interchangeably.

\section{Pharmacological approach of the role of PI3K}

The PI3K signaling pathway is important in the potentiating or priming effect of insulin-like growth factor-1 and thrombopoietin on platelet activation (34-35). Moreover, TLR receptors are known to triggers PI3K stimulation (30) and anti- $\beta 2$ GPI antibody- $\beta 2$ GPI complexes have been suggested to activate Akt downstream of the GPIb receptor in platelets (14). Therefore, we tested two pan-PI3K inhibitors, wortmaninn and LY294002, and two isoforms-selective inhibitors targeting either class IA PI3K $\alpha$ (INK-1117) or class IA PI3K $\beta$ (TGX-221) on the potentiating effect of aPL IgG on platelet aggregation induced by low concentrations of thrombin. As shown in Figure 3, all inhibitors strongly decreased the aPL effect, suggesting that the $\mathrm{PI} 3 \mathrm{~K} \alpha$ and $\beta$ isoforms are both required (while they are not necessary for thrombininduced platelet aggregation (23), and data not shown). It is noteworthy that at a concentration expected to spare PI3K $\alpha$ and $\beta$ activities, the PI3K $\delta$ inhibitor CAL-101 (2.5 nM), had no significant effect on the amplification of platelet activation by aPL IgG (data not shown).

To investigate the role of these PI3K on the potentiating effect of aPL on thrombus formation under flow conditions we treated whole blood by INK-1117 and by AZD6482, a selective inhibitor of PI3K $\beta$ more stable than TGX-221 in blood (36). Again, each inhibitor strongly reduced the effect of aPL IgG (Figure 3B and C).

Addition of aPL IgG strongly increased Akt phosphorylation at $\mathrm{Ser}^{473}$ in comparison to the effect of thrombin at low concentration, alone or in the presence of control IgG (Figure 4). Consistent with the result obtained in functional assays, Akt phosphorylation was inhibited by wortmannin or LY294002 as well as by PI3K $\alpha$ and $\beta$ inhibitors (Figure 4A and B). Moreover, 
GPIb $\alpha$ and TLR2 blocking antibodies efficiently inhibited Akt phosphorylation induced by aPL IgG (Figure 4B).

Overall, these data show that aPL IgG activate Akt in a class I PI3K $\alpha$ - and $\beta$-dependent and non-redundant manner and that this pathway is important in mediating the potentiating effect of aPL IgG on platelet aggregation and thrombus growth.

\section{$\underline{\text { Genetic approach to assess the role of class I PI3K isoforms }}$}

To assess the role of class IA PI $3 \mathrm{~K} \alpha$ and $\beta$ by genetic approaches, we used mice with selective $\mathrm{p} 110 \alpha$ or $\mathrm{p} 110 \beta$ inactivation in the megakaryocyte lineage (25-26). Consistent with previous reports $(3,8,37)$, we observed a potentiating effect of aPL IgG on mouse platelet aggregation in vitro (Figure 5A). In the absence of either class IA PI3K $\alpha$ or $\beta$, the weak platelet aggregation induced by 0.035 thrombin alone was not significantly modified whereas the potentiating effect of aPL IgG on platelet aggregation induced by this low dose of thrombin was no longer observed (Figure 5A). Moreover, the aPL-induced increase in Akt phosphorylation at $\operatorname{Ser}^{473}$ was abolished in mouse platelets deficient in PI3K $\alpha$ or $\beta$ (Figure 5B).

Whole blood from control or genetically-modified mice was then perfused on a collagen matrix under arterial flow conditions and platelet adhesion and thrombus formation were analyzed (Figure 5C). Addition of aPL IgG to whole blood from wild-type mice significantly increased platelet adhesion. In contrast, the absence of either PI3K $\alpha$ or $\beta$ in platelets from genetically modified mice abolished the potentiating effect of aPL. Overall, the results obtained using mouse models are in line with the data obtained using pharmacological PI3K inhibitors.

\section{DISCUSSION}


The current management of patients with APS relies on the use of long-term anticoagulation which is not always sufficient to prevent thrombosis, and may cause bleeding. In order to develop targeted therapeutic strategies, it is important to decipher the molecular mechanisms induced by pathogenic aPL. APL are thought to first associate with $\beta 2 \mathrm{GP} 1$, more precisely to the domain I of the molecule in appropriate conformation (38). Dimerized $\beta 2 \mathrm{GP} 1$ antibody complex then binds to membrane receptors on endothelial cells, monocytes and platelets, thereby mediating their activation. Experimental data obtained in animal models strongly suggest that aPL IgG purified from patients with APS are not sufficient alone to induce thrombosis $(3,9-10)$. However, in combination with other stimuli, aPL IgG strongly amplify platelet responses to suboptimal concentrations of physiological agonists (18). This double hit model is relevant to the risk of thrombosis in humans. Proulle et al. (17) have recently highlighted the pivotal role of platelets in the pathological mechanism of APS. They have shown that upon injury of arterioles from the cremaster muscle the $\beta 2 \mathrm{GP} 1$-antibody- $\beta 2 \mathrm{GP} 1$ complexes bind to the platelet thrombus, and not the endothelium, leading to an amplification of platelet activation, followed by endothelium activation and fibrin formation. Thus, in this experimental model, platelets are the first target of the $\beta 2 \mathrm{GP} 1$-antibody- $\beta 2 \mathrm{GP} 1$ complexes. This suggests that increased fibrin generation and endothelium activation by aPL are plateletdependent.

To study the mechanisms by which aPL IgG amplify platelet activation, we used light transmission platelet aggregometry with subthreshold concentrations of thrombin, the most potent platelet agonist, and quantified thrombus formation under flow in a microfluidic system (whole citrated blood perfused on a collagen matrix at arterial shear rate). In the two systems, the addition of aPL IgG, and not control $\mathrm{IgG}$, potentiated platelet aggregation and thrombus formation. As $\beta 2 \mathrm{GP} 1$ was abundant on the surface of washed platelets, it was likely that the signal was mediated by $\beta 2 \mathrm{GP} 1$-antibody- $\beta 2 \mathrm{GP} 1$ complexes. To confirm this, we 
studied the requirement of GP1b, one of the platelet receptors involved in the interaction with $\beta 2$ GP1 (14-16,19-20). As expected, blocking antibodies to GPIb $\alpha$ specifically prevented platelet sensitization by aPL IgG. Since TLR2 has been proposed as a membrane receptor for $\beta 2 \mathrm{GP} 1$ on endothelial cells and mediates monocytes and endothelial cells activation by aPL $\operatorname{IgG}(3,12)$, we hypothesized that TLR2, present on platelets $(30,31)$, could also be a receptor for $\beta 2 \mathrm{GP} 1$-antibody- $\beta 2 \mathrm{GP} 1$ complexes. Using blocking antibodies, we found that TLR2 is indeed implicated in the effect of aPL IgG on platelet sensitization, both when platelets are in suspension and under conditions of flow on a collagen matrix. In addition, both GP1b and TLR2 were required for this effect and are not redundant. The same cooperative effect has been previously described between Gp1b and the lipid scavenger ApoER2 at the platelet surface $(15,16,20)$, suggesting that the clustering of several receptors is required for proper sensitization of platelets by non physiological agonists such as antigen-antibody complexes.

The PI3K/Akt cascade has been proposed as an important signaling pathway downstream GP1b and $\beta 2 \mathrm{GP} 1$ antibody complexes (14). This is also the case for ApoER2 in other cell types (39). As far as TLR2 is concerned, its activation by pathogen-associated molecular patterns (PAMS) induces intracellular signals leading to platelet activation and TLR2 triggering by the agonist Pam3 has been shown to activate class IA PI3K and Akt (30-31). We show here that aPL IgG strongly amplify Akt phosphorylation induced by low doses of thrombin. This amplification is no longer observed in the presence of blocking antibodies to TLR2 or GPIb $\alpha$ suggesting that both receptors use the same pathway, namely PI3K/Akt, when stimulated by aPL IgG.

Using selective inhibitors of $\mathrm{PI} 3 \mathrm{~K} \alpha$ and $\beta$, we found that both play a critical role in the amplification effect of aPL on Akt activation, platelet aggregation induced by low doses of thrombin and thrombus formation under arterial flow. We confirm these data in the same experimental systems, using washed platelets or whole blood from PI3K $\alpha$ - or $\beta$ - deficient 
mice. Indeed, the potentiating effect of aPL on thrombin-induced aggregation and on thrombus formation under flow was no longer observed in these mice.

Taken together, our data indicate that PI3K $\alpha$ and $\beta$ have a complementary and non-redundant role in the aPL-induced amplification of platelet activation. Whether the two isoforms are required to reach a high level of activation of their common effector Akt, or whether each one activates specific downstream effectors remains to be established. Our study also highlights the potential applications of the flow-based thrombus formation assay to screen potential drugs preventing the aPL effect on platelets or to ex-vivo analyze the prothombotic effect of aPL antibodies in patients.

In conclusion, our data show that aPL-induced platelet sensitization requires TLR2 in addition to GPIb and identify for the first time the equal contribution of the two PI3K isoforms $\alpha$ and $\beta$ of class IA PI3K as critical players in the aPL-effects on platelets. PI3K $\beta$ inhibitors have been proposed as potential antithrombotic drugs (40), preventing occlusive thrombus formation with limited increase in bleeding risk and acceptable safety in humans (36). Our results suggest that targeting class IA PI3K $\beta$ and/or $\alpha$ could also be an interesting strategy to prevent the prothrombotic effects of aPL in APS.

\section{Acknowledgements}

The authors thank the Zootechnie Core Facility UMS US006 / Inserm of anexplo-Genotoul. This work was supported by Inserm, by Fondation pour la Recherche Médicale (grant number DPC20111122988) and by the Toulouse Hospital (AOL n 13-202-02).

Work in the laboratory of B.V. is supported by the UK BBSRC (BB/I007806/1) and the UK NIHR University College London Hospitals Biomedical Research Centre. B.P. is a scholar of the Institut Universitaire de France. 


\section{REFERENCES}

1- Galli M, Luciani D, Bertolini G, et al. Anti-beta 2-glycoprotein I, antiprothrombin antibodies, and the risk of thrombosis in the antiphospholipid syndrome. Blood 2003; 102: $2717-23$.

2- de Groot PG, Urbanus RT. The significance of autoantibodies against $\beta 2$-glycoprotein I. Blood 2012; 120: 266-74.

3- Arad A, Proulle V, Furie RA, et al. $\beta_{2}$-Glycoprotein-1 autoantibodies from patients with antiphospholipid syndrome are sufficient to potentiate arterial thrombus formation in a mouse model. Blood 2011; 117: 3453-9.

4- De Laat B, Derksen RH, van Lummel M, et al. Pathogenic anti-beta2-glycoprotein I antibodies recognize domain I of beta2-glycoprotein I only after a conformational change. Blood 2006; 107: 1916-1924.

5- Forastiero R, Martinuzzo M, de Larrañaga G, et al. Anti- 32 glycoprotein I antibodies from leprosy patients do not show thrombogenic effects in an in vivo animal model. $\mathbf{J}$ Thromb Haemost 2011; 4: 859-61.

6- Ioannou Y, Pericleous C, Giles I, et al.. Binding of antiphospholipid antibodies to discontinuous epitopes on domain I of human beta(2)-glycoprotein I: mutation studies including residues R39 to R43. Arthritis Rheum 2007; 56: 280-290.

7- Bontadi A, Ruffatti A, Falcinelli E, et al. Platelet and endothelial activation in catastrophic and quiescent antiphospholipid syndrome. Thromb Haemost 2013; 109: 901-8.

8- Pierangeli SS and Harris EN. Antiphospholipid antibodies in an in vivo thrombosis model in mice.Lupus 1994; 3: 247-51.

9- Ramesh S, Morrell CN, Tarango C, et al. Antiphospholipid antibodies promote leukocyte-endothelial cell adhesion and thrombosis in mice by antagonizing eNOS via 
ß2GPI and apoER2. J Clin Invest 2011; 121: 120-131.

10-Romay-Penabad Z, Aguilar-Valenzuela R, Urbanus RT, et al. Apolipoprotein E receptor 2 is involved in the thrombotic complications in a murine model of the antiphospholipid syndrome. Blood 2011; 117: 1408-14.

11- Fischetti F, Durigutto P, Pellis V, et al. Thrombus formation induced by antibodies to beta2-glycoprotein I is complement dependent and requires a priming factor. Blood 2005; 106: 2340-46.

12-Satta N, Dunoyer-Geindre S, Reber G, et al. The role of TLR2 in the inflammatory activation of mouse fibroblasts by human antiphospholipid antibodies Blood 2007; 109: 1507-14.

13- Allen KL, Fonseca FV, Betapudi V, et al. A novel pathway for human endothelial cell activation by antiphospholipid/anti- $\beta 2$ glycoprotein I antibodies. Blood 2012; 119 : 884-93.

14-Shi T, Giannakopoulos B, Yan X, et al. Anti-beta2-glycoprotein I antibodies in complex with beta2-glycoprotein I can activate platelets in a dysregulated manner via glycoprotein Ib-IX-V. Arthritis Rheum 2006; 54: 2558-67.

15-Pennings MT, Derksen RH, van Lummel M, et al. Platelet adhesion to dimeric betaglycoprotein I under conditions of flow is mediated by at least two receptors: glycoprotein Ibalpha and apolipoprotein E receptor 2'. J Thromb Haemost 2007; 5: 369-77.

16-Lutters BC, Derksen RH, Tekelenburg WL, et al.. Dimers of beta 2-glycoprotein I increase platelet deposition to collagen via interaction with phospholipids and the apolipoprotein E receptor 2'. J Biol Chem 2003; 278: 33831-8. 
17-Proulle V, Furie RA, Merrill-Skoloff G, et al.. Platelets are required for enhanced activation of the endothelium and fibrinogen in a mouse thrombosis model of APS. Blood 2014; 124: 611-22.

18- Vega-Ostertag M, Harris EN, Pierangeli SS. Intracellular events in platelet activation induced by antiphospholipid antibodies in the presence of low doses of thrombin. Arthritis Rheum 2004; $50: 2911-9$.

19- Jankowski M, Vreys I, Wittevrongel C, et al. Thrombogenicity of beta 2-glycoprotein I-dependent antiphospholipid antibodies in a photochemically induced thrombosis model in the hamster. Blood 2003; 101: 157-62.

20- Urbanus RT, Pennings MT, Derksen RH, et al. Platelet activation by dimeric beta2glycoprotein I requires signaling via both glycoprotein Ibalpha and apolipoprotein E receptor 2'. J Thromb Haemost 2008; 6: 1405-12.

21-B Vanhaesebroeck, J Guillermet-Guibert, M Graupera, et al.. The emerging mechanisms of isoform-specific PI3K signalling. Nature Rev Mol Cell Biol 2010; 11 : $329-341$.

22-Laurent PA, Severin S, Gratacap MP, et al. Class I PI 3-kinases signaling in platelet activation and thrombosis: PDK1/Akt/GSK3 axis and impact of PTEN and SHIP1. Adv Biol Regul 2014; 54 : 162-74.

23- Jackson SP, Yap CL, Anderson KE. Phosphoinositide 3-kinases and the regulation of platelet function. Biochem Soc Trans $2004 ; 32$ : 387-392.

24- Miyakis S, Lockshin MD, Atsumi T, et al. International consensus statement on an update of the classification criteria for definite antiphospholipid syndrome (APS). J Thromb Haemost 2006; 4 : 295-306

25-Martin V, Guillermet-Guibert J, Chicanne G, et al. Deletion of the p110beta isoform of phosphoinositide 3-kinase in platelets reveals its central role in Akt activation and 
thrombus formation in vitro and in vivo. Blood 2010; 115: 2008-13.

26-Laurent PA, Séverin S, Hechler B, et al. Platelet PI3K $\beta$ and GSK3 regulate thrombus stability at high shear rate. Blood 2015; 125: 881-888.

27-Soulet C, Hechler B, Gratacap MP, et al. C. A differential role of the platelet ADP receptors $\mathrm{P}_{2} \mathrm{Y}_{1}$ and $\mathrm{P} 2 \mathrm{Y}_{12}$ in Rac activation. J Thromb Haemost 2005; 3: 2296-2306.

28- Alard JE, Gaillard F, Daridon C, et al. TLR2 is one of the endothelial receptors for beta 2-glycoprotein I. J Immunol 2010; 185: 1550-7.

29- Poulton K, Rahman A, Giles I. Examining how antiphospholipid antibodies activate intracellular signaling pathways: a systematic review. Semin Arthritis Rheum 2012; 41:720-36.

30-Blair P, Rex S, Vitseva O, et al. Stimulation of Toll-like receptor 2 in human platelets induces a thromboinflammatory response through activation of phosphoinositide 3kinase. Circ Res 2009; 104: 346-54.

31-Fälker K, Klarström-Engström K, Bengtsson T, et al. The toll-like receptor 2/1 (TLR2/1) complex initiates human platelet activation via the src/Syk/LAT/PLC $\gamma 2$ signalling cascade. Cell Signal 2014; 2: 279-86.

32- Beaulieu LM, Freedman JE. The role of inflammation in regulating platelet production and function: Toll-like receptors in platelets and megakaryocytes. Thromb Res 2010; 125: 205-9.

33-de Groot PG, Meijers JC. $\beta(2)$-Glycoprotein I: evolution, structure and function. J Thromb Haemost 2011; 7: 1275-84.

34-Blair TA, Moore SF, Williams CM, et al. Phosphoinositide 3-kinases p110 $\alpha$ and p110 $\beta$ have differential roles in insulin-like growth factor-1-mediated Akt phosphorylation and platelet priming. Arterioscler Thromb Vasc Biol 2014; 34: 16818. 
35-Pasquet JM, Gross BS, Gratacap MP, et al. Thrombopoietin potentiates collagen receptor signaling in platelets through a phosphatidylinositol 3-kinase-dependent pathway. Blood 2000; 95: 3429-34.

36- Nylander S, Kull B, Björkman JA, et al. Human target validation of phosphoinositide 3-kinase (PI3K)beta: effects on platelets and insulin sensitivity, using AZD6482 a novel PI3Kbeta inhibitor. J Thromb Haemost 2012; 10: 2127-36.

37-Pierangeli SS, Liu SW, Anderson G, et al. Thrombogenic properties of murine anticardiolipin antibodies induced by beta 2 glycoprotein 1 and human immunoglobulin $\mathrm{G}$ antiphospholipid antibodies. Circulation 1996; 94: 1746-51.

38-Banzato A, Pozzi N, Frasson R, et al. Antibodies to Domain I of $\beta(2)$ Glycoprotein I are in close relation to patients risk categories in Antiphospholipid Syndrome (APS). Thromb Res 2011; $128: 583-6$.

39-Herz J, Chen Y, Masiulis I, et al. Expanding functions of lipoprotein receptors. J. Lipid Res 2009; 50 : S287-92.

40- Jackson SP, Schoenwaelder SM, Goncalves I, et al. PI 3-kinase p110beta: a new target for antithrombotic therapy. Nat Med 2005; 11: 507-14. 


\section{FIGURE LEGENDS}

Figure 1: aPL strongly amplify platelet aggregation and thrombus formation. (A) Washed platelets aggregation induced by a low dose of thrombin $(0.035 \mathrm{U} / \mathrm{ml})$ is increased by IgG from three APS patients $(16 \mu \mathrm{g} / \mathrm{ml})$. As controls, $\mathrm{IgG}$ from three healthy donors (16 $\mu \mathrm{g} / \mathrm{ml}$ ) had no effect. T: Thrombin, C: control IgG from healthy donors (1 to 3), aPL: IgG from APS patients (1 to 3). A typical aggregation response illustrating the effect of aPL1 is also shown (right panel). (B,C,D) DIOC $_{6}$-labeled platelets in citrated whole blood were perfused over a collagen matrix at a wall shear rate of $60 \mathrm{dyn} / \mathrm{cm}^{2}\left(1,500 \mathrm{~s}^{-1}\right)$ for $2.5 \mathrm{~min}$ in the absence (Control) or presence of IgG from APS patients or from healthy donors. Surface area covered by platelets was measured at two surface locations and is shown for IgG from healthy donor 2 and APS patient 2 (B). Thrombi volumes were measured at two surface locations in the presence of IgG from the three APS patients and the three healthy donors (C). The right panels (D) show a representative image of the thrombi formed after $2.5 \mathrm{~min}$. They were visualized with a 40x long working distance objective and imaged by fluorescence microscopy (scale bar: $10 \mu \mathrm{m}$ ). Results are mean values \pm SEM from five (A and C) and three (B) independent experiments. Significant differences: $*: \mathrm{p}<0.05 ; * *: \mathrm{p}<0.01 ; * * *: \mathrm{p}<0.001$ versus control.

Figure 2: GPIb $\alpha$ and TLR2 are required to mediate the thrombotic effect of aPL. (A) The potentiating activity of aPL (1 to 3 ) on platelet aggregation induced by a low concentration of thrombin $(\mathrm{T}: 0.035 \mathrm{U} / \mathrm{ml})$ is prevented by preincubation of washed human platelets with blocking antibodies to CD42b and TLR2, used at 1.8 and $6.6 \mu \mathrm{g} / \mathrm{ml}$, respectively. (B) CD42b and TLR2 blocking antibodies (4.5 and $20 \mu \mathrm{g} / \mathrm{ml}$, respectively) or vehicle (Control) were added to whole blood and their effect on aPL (1 to 3)-induced increase 
in thrombus formation on a collagen matrix under arterial flow $\left(60 \mathrm{dyn} / \mathrm{cm}^{2}\right.$ or $\left.1,500 \mathrm{~s}^{-1}\right)$ was measured. Thrombi volumes (B) were measured at 2 different locations. Results are expressed as percentage of aPL effect and are mean \pm SEM of 5 (A) and 3 (B) independent experiments. Significant differences: $*: \mathrm{p}<0.05 ; * *: \mathrm{p}<0.01 ; * * *: \mathrm{p}<0.001$ versus aPL effect.

Figure 3: Involvement of platelet class IA PI3K $\alpha$ and PI3K $\beta$ in aPL-induced thrombotic effect. (A) The potentiating activity of aPL on platelet aggregation induced by a low concentration of thrombin $(0.035 \mathrm{U} / \mathrm{ml})$ is prevented by preincubation of washed human platelets with pan PI3K inhibitors (wortmannin and LY294002) or by selective inhibitors of PI3K $\alpha$ (INK-1117; $0.5 \mu \mathrm{M}$ ) or PI3K $\beta$ (TGX-221 $0.5 \mu \mathrm{M}$ ). (B, C) Inhibition of PI3K $\alpha$ (by 1 $\mu \mathrm{M}$ INK1117) or PI3K $\beta$ (by $5 \mu \mathrm{M}$ AZD-6482, a stable analogue of TGX-221 in whole blood) also prevent aPL-induced increase in thrombus formation on a collagen matrix under arterial flow in whole blood $\left(60 \mathrm{dyn} / \mathrm{cm}^{2}\right.$ or $\left.1,500 \mathrm{~s}^{-1}\right)$. Similar effects of these inhibitors were obtained at $20 \mathrm{dyn} / \mathrm{cm}^{2}$ or $500 \mathrm{~s}^{-1}$ (not shown). Scale bar : $10 \mu \mathrm{m}$. Thrombi volumes (B) were measured at 2 different locations. Results are express as mean \pm SEM of 5 (A) and 3 (B) independent experiments. Significant differences: $* * *: p<0.001$. Representative images of thrombi visualized with a 40x long working distance objective in real time are shown (C).

Figure 4: Akt activation in aPL-induced platelet activation. The potentiating activity of aPL on the phosphorylation of Akt-Ser ${ }^{473}$ in platelet activated by a low concentration of thrombin $(0.035 \mathrm{U} / \mathrm{ml})(\mathrm{A})$ is prevented by preincubation of washed human platelets with pan-PI3K inhibitors (wortmannin and LY294002), selective inhibitors of PI3K $\alpha$ (INK-1117) or PI3K $\beta$ (TGX-221) and with blocking antibodies to CD42b $(1.8 \mu \mathrm{g} / \mathrm{ml})$ and TLR2 (6.6 $\mu \mathrm{g} / \mathrm{ml}$ ) (B). Platelet lysates were submitted to immunoblotting with anti-Akt-Ser $(\mathrm{P})^{473}$ or total Akt antibodies, as indicated. Quantification by densitometric analysis of the Western blots is 
shown (B). Results are express as mean \pm SEM of 3 (B) independent experiments. Significant differences: $* *: \mathrm{p}<0.01 ; * * *: \mathrm{p}<0.001$

Figure 5: Deficiency in class IA PI3K $\alpha$ or PI3K $\beta$ in mice platelets abolishes the thrombotic effect of aPL. (A) The potentiating activity of aPL (vs control IgG, C) on mouse platelet aggregation induced by a low concentration of thrombin $(\mathrm{T}: 0.035 \mathrm{U} / \mathrm{ml})$ is prevented by genetic loss of PI3K $\alpha$ or PI3K $\beta$. (B) Platelet lysates were submitted to immunoblotting with anti-Akt-Ser $(\mathrm{P})^{473}$ and total Akt antibodies. After quantification by densitometric analysis of the Western blots results are expressed as mean \pm SEM of 3 independent experiments. (C) DIOC $_{6}$-labeled platelets in citrated whole blood from wild type mouse or mouse deficient in PI3K $\alpha$ or PI3K $\beta$ in platelets were perfused over a collagen matrix at a wall shear rate of $60 \mathrm{dyn} / \mathrm{cm}^{2}\left(1,500 \mathrm{~s}^{-1}\right)$ for $2.5 \mathrm{~min}$ in the presence of aPL or control $\mathrm{IgG}$. Surface area covered by thrombi and thrombi volumes were measured at 2 surface locations. Results are express as mean \pm SEM of 3 independent experiments. Significant differences: $*: p<0.05$

\section{Supplementary Figure 1: Presence of the $\beta 2$ GPI protein at the surface of washed human}

platelets. Washed human platelets $\left(8.10^{6} / 20 \mu \mathrm{l}\right)$ were incubated with a mouse anti-human $\beta 2 \mathrm{GP} 1$ antibody $(50 \mu \mathrm{g} / \mathrm{ml})$ for $30 \mathrm{~min}$ in absence or presence (when indicated) of plasma from the same blood $(10 \mu \mathrm{l})$, or recombinant $\beta 2 \mathrm{GP} 1(50 \mu \mathrm{g} / \mathrm{ml})$. Platelets were then stained with FITC conjugated mouse anti-human secondary antibody or mouse IgG1 isotype as control (Invitrogen) and analyzed using a LSRFortessa ${ }^{\mathrm{TM}}$ Cell analyzer flow cytometer and Diva software (Becton Dickinson).

Supplementary Figure 2: TLR2 blocking antibodies inhibit the thrombotic effect of aPL. DIOC $_{6}$-labeled platelets in whole blood from healthy donors were perfused over a collagen 
matrix at a wall shear rate of $60 \mathrm{dyn} / \mathrm{cm}^{2}\left(1,500 \mathrm{~s}^{-1}\right)$ for $2.5 \mathrm{~min}$ in the presence of $\mathrm{IgG}$ from APS patient 3 (aPL3) or from healthy donor 3 (C3). Surface area covered by platelets was measured at two surface locations. Addition of CD42b (A) and TLR2 (B) blocking antibodies (20 and $4.5 \mu \mathrm{g} / \mathrm{ml}$ ) in whole blood prevents aPL3-induced increase in surface area covered by platelets on a collagen matrix under arterial flow $\left(60 \mathrm{dyn} / \mathrm{cm}^{2}\right.$ or $\left.1,500 \mathrm{~s}^{-1}\right)$. Significant differences: $* * *: p<0.001$ versus aPL effect. Similar effects were observed with $\operatorname{IgG}$ from APS patient 1 and 2 (not shown). 